\title{
ORIENTATION BY BULK MESSENGER SENSORS IN AQUATIC VERTEBRATES
}

\author{
J. E. Bardach, G. H. Johnson and J. H. Todd \\ School of Natural Resources \\ The University of Michigan \\ Ann Arbor, Mich.
}

All higher animals have evolved sense organs to detect minute amounts of chemicals in their environments. The stimuli they perceive affect their behavior in various ways: in locating of food, in orientation in home ranges or territories, in detection of the opposite sex, and even in the recognition of individuals of the same species. Among some fishes, the chemical sense organs are extremely well developed. The olfactory acuity of the eel (Anguilla anguilla) is such that the animal has been trained to respond to beta phenylethyl alcohol in a solution of $1.77 \times 10^{3}$ molecules per cubic centimeter of water (Teichmann, 1962). This, as the late Dr Teichmann so vividly stated, corresponds to a cubic centimeter of scent being dispersed in 58 times the water volume of the Lake of Constance. At this dilution, only two molecules at best would have been at one time in the nose of his small experimental eels, which had a nasal volume of only one cubic millimeter. Other fishes, however, do not appear to use their noses at all; the stickleback, for example, is anosmic.

The other chemical sense, taste, is also very acute. It has been established that certain minnows have thresholds for taste several orders of magnitude lower than for humans (Glaser, 1966). Other fishes, which have many more taste sensors than these minnows, are believed to have taste thresholds that come close to olfactory ones. Sensory acuity is often reflected in the anatomy of the receptor organ. The fishes best able to smell have the olfactory epithelium thrown into the largest number of folds (e.g. the eel, Frgure 1) and have well developed mechanisms to insure the passage of water over the receptor surfaces. Those best able to taste possess a large number of typical vertebrate taste buds (FIGURE 2) distributed all over their bodies, including the tail.

In addition to large numbers of receptor cells for bulk messengers and related to the acuity of performance of smell and taste orientation, there are various adaptations that allow a fish to make comparisons of scent or taste substance concentrations in space and/or time. The hammerhead shark (FIGURE 3), for instance, bears its two nares at the extremities of its peculiarly broadened, wedge-shaped head. Directional detection of scent to the right and left of this shark is further enhanced by its sinuous swimming movements. 

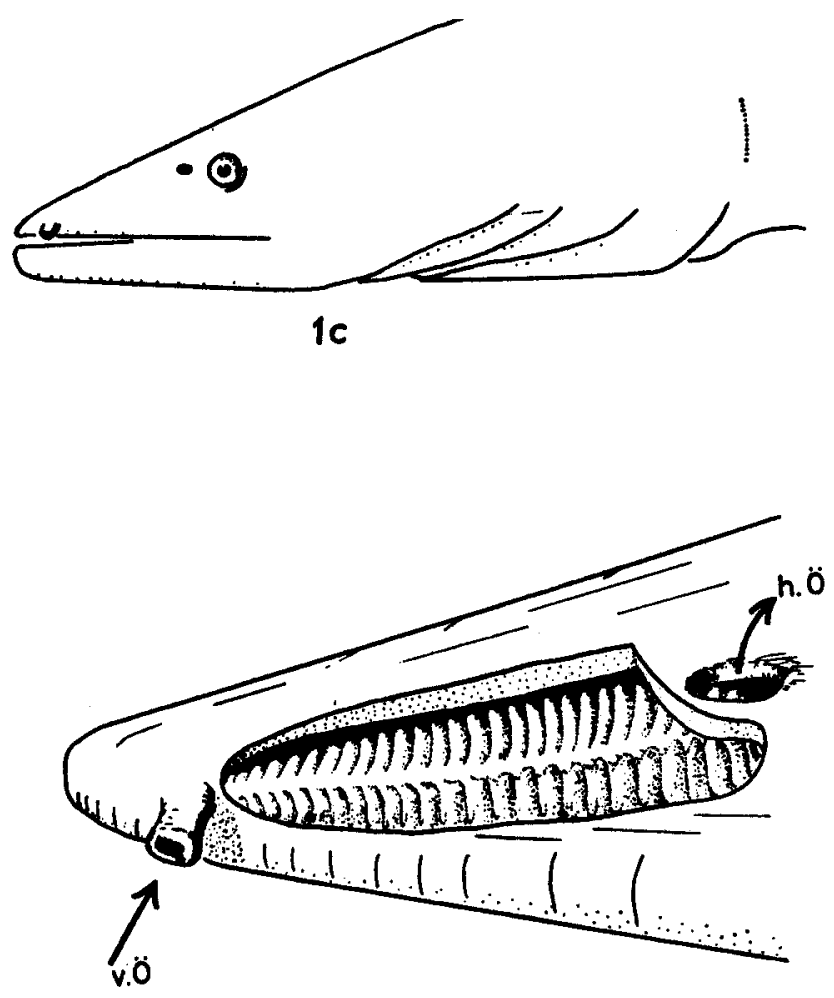

FIGURE 1. Nasal anatomy of the eel (Anguilla anguilla). Water is drawn in through the anterior opening (v.ö) of the nose, passed over numerous olfactory folds, and discharged through the posterior opening (h.ö). (From H. Teichmann, 1962. Die Umschau, in: Wissenschaft in Technik, Frankfurt am Main 62: 568.)

Moray eels not only have their anterior nares fashioned into moveable intake tubes (FIGURE 1) but also move their heads to and fro.

Selective unilateral neural control over receptor performance and accessory olfactory structures has also been demonstrated. Higher neural centers through efferent pathways can modify afferent responses in either the right or left olfactory tract (Döving, 1966). In addition, selective speedup or slowdown of water flow through either right or left naris is achieved through control of accessory olfactory structures, such as cilia or hydraulic devices (C. Chen \& J. E. Bardach, unpublished).

Analysis of swimming patterns in response to chemical stimuli in olfactory search (by tuna, for example, which are fast swimmers and have no external taste sensors) suggests that the animals rely on comparisons in time in spite of the above-mentioned mechanisms that enhance the discrimination of differences in scent concentrations to the right or left of them. They employ the 
often described figure-eight pattern of search in zoning in on the target, only to overshoot and go beyond the location of the scent (FIGURE 4) because they swim too fast. (J. E. Bardach \& R. Gooding, unpublished).

Orientation to an olfactory stimulus seems to rely more on a comparison of successive neural events; however, orientation by taste, among those fishes that possess external taste sensors, can proceed by simultaneous assessment of the spatial distribution of the stimulus along or across the body. The group of fishes that is anatomically best equipped for such a detection of a chemical gradient bears not only a profusion of taste buds on head, back, flanks, and tail, but also has them concentrated on appendages such as barbels, and often on modified filamentous fins or fin rays. Usually the concentration of these taste sensors is greatest at the apices of the appendages: Thus, these animals, by nature long and slender as most fishes are, can sample close to or at their

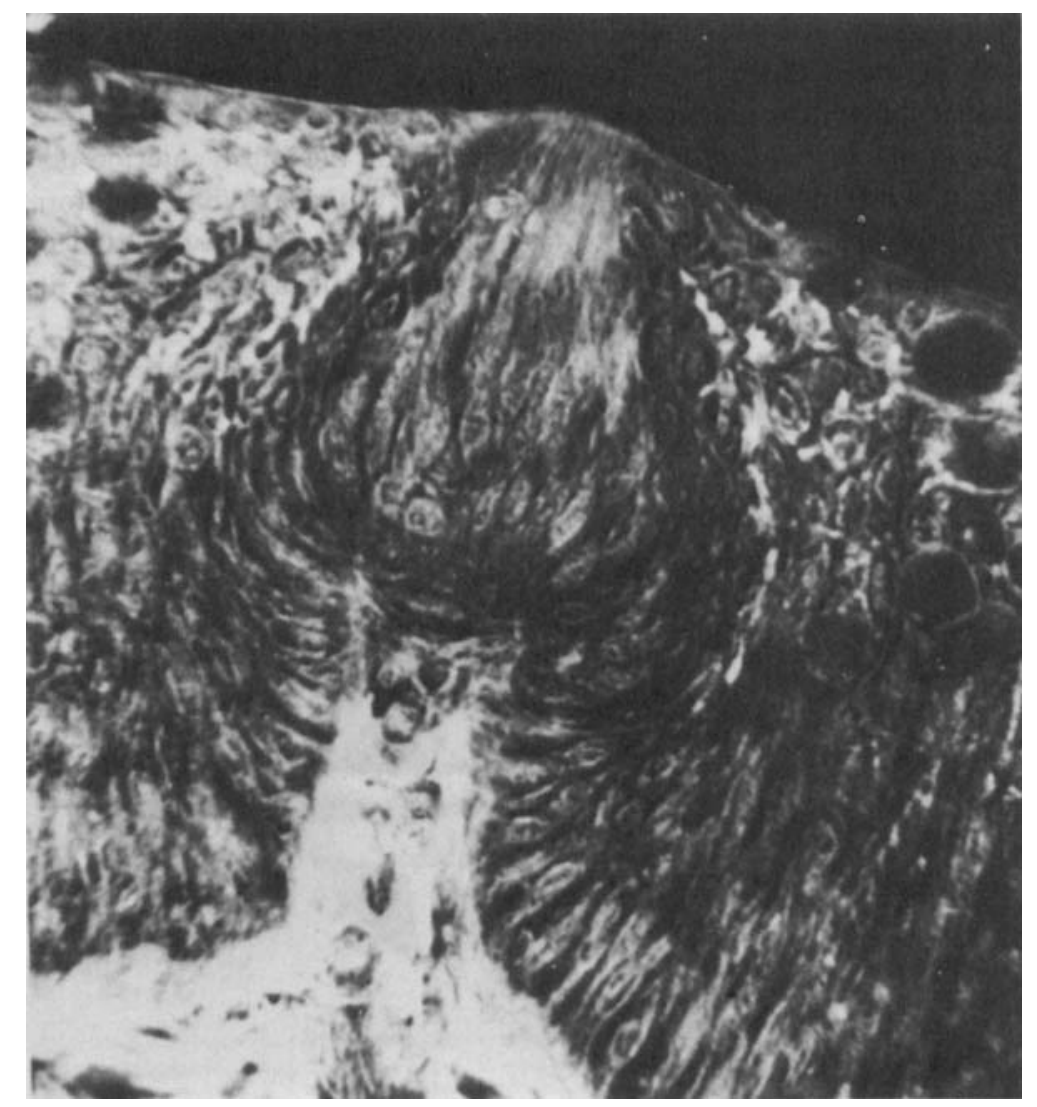

FIGURE 2. Taste bud from the barbel of a yellow bullhead (Ictalurus natalis). 
front ends a field that is many times wider than their body proper. In extreme cases, as in some Asian and South American catfishes, the maxillary barbel, when folded back, reaches the caudal peduncle (FIGURE 5). The barbels can be spread laterally or directed forward to points at which tasty bulk messengers can be intercepted at the corners of an isosceles triangle, the long side of which is at the front of the animal and twice its length. The distribution of individual receptors, as well as the swimming patterns of the animals when orienting in a chemical gradient, substantiates the concept that concentration differences are indeed assessed by simultaneous comparison of the inputs from different groups of taste buds.

On a common bullhead (FIGURE 6), the barbels have the highest density of tastebuds, averaging approximately $1,675 / \mathrm{cm}^{2}$, with the maximum concentration at the very tips, where up to $3,400 / \mathrm{cm}^{2}$ have been counted. The next highest concentration, averaging approximately $225 / \mathrm{cm}^{2}$ is found on the tail region. On the back and on the flanks the concentrations are less dense, averaging about $165 / \mathrm{cm}^{2}$ and $120 / \mathrm{cm}^{2}$, respectively. Ten counts were made in each of the outlined body regions (FIGURE 6); there were no significant individual differences among the three specimens, yielding these counts. It is not surprising that the taste buds are densest at the most anterior points in the animal's field of motion where they are most valuable. While no information exists on the central integration of taste stimuli, the even distribution of taste buds on the long axis of the body suggests that small local differences in foreaft direction can also be assessed.

Photographic recording of the swimming paths of catfishes in response to a chemical stimulus were made in slow currents and in still water. The

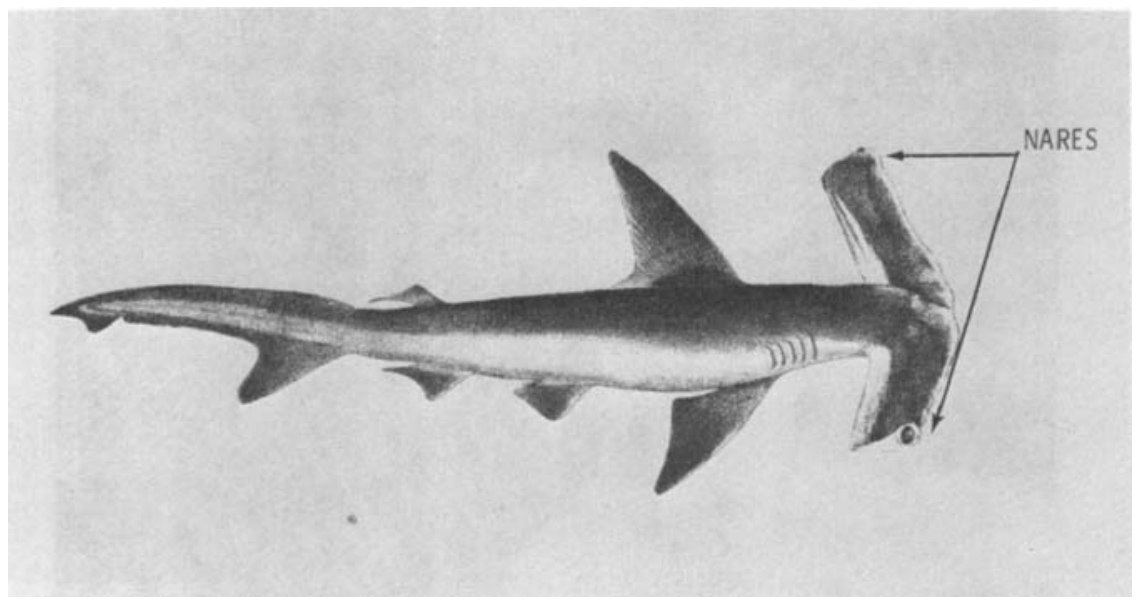

Figure 3. Hammerhead shark (Zygaena blochii) showing the location of its two nares at the extremities of its peculiarly wedge-shaped head. 


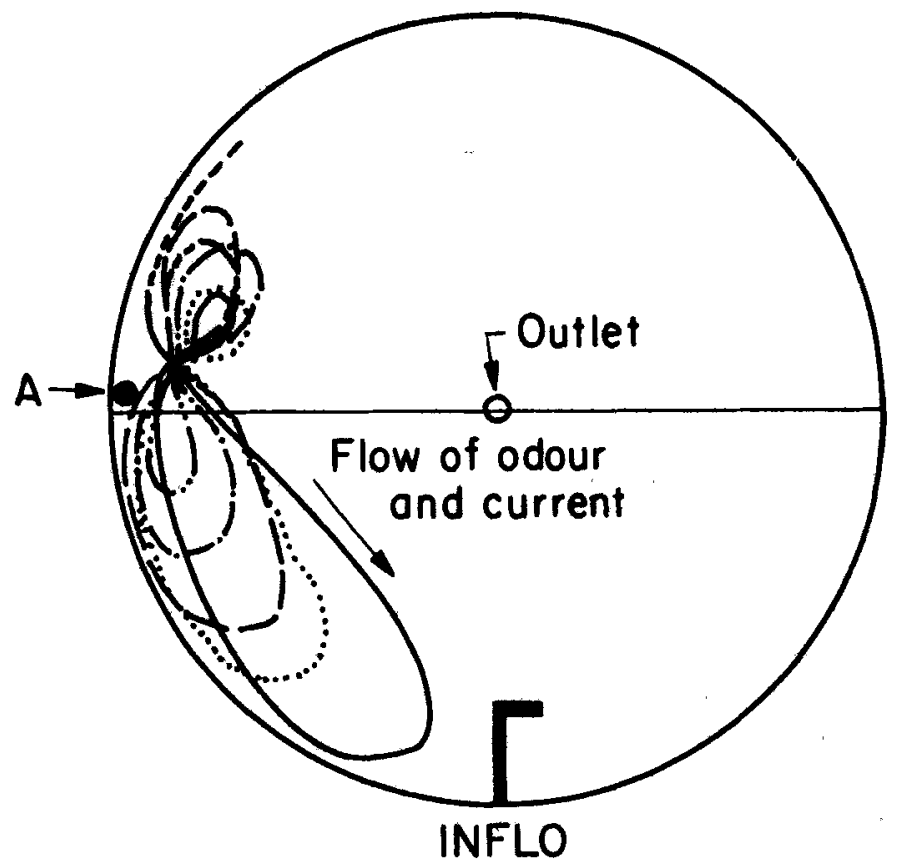

FIGURE 4. Figure-eight search pattern of skipjack tuna (Euthynnus affinus) swimming in a tank 16 meters in diameter at about three meters/second, locating a source of scent introduced at point $A$.



FIGURE 5. Asian catfish (Macrones microphthalmus), showing the long maxillary barbel which can be directed forward. 


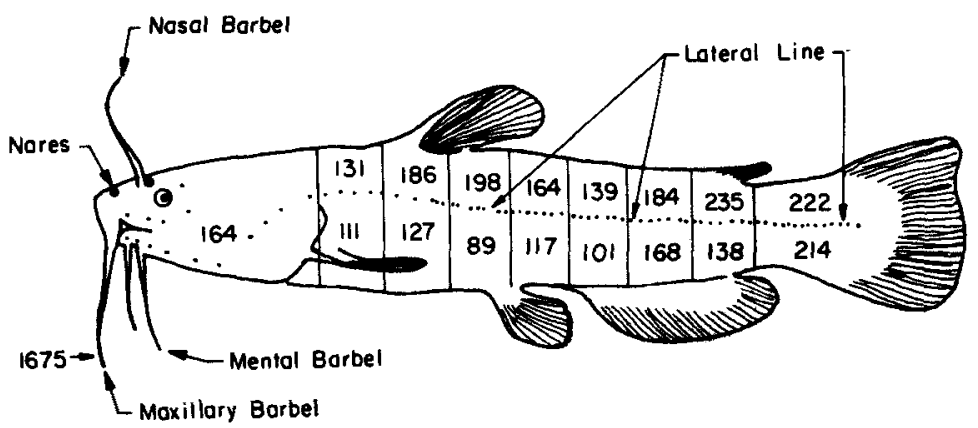

FIGURE 6. Average number of taste buds per square centimeter of various regions of the body in the brown bullhead (lctalurus nebulosus).

animals were blinded, and small fluorescent plastic dises were affixed to the tops of their heads. To further eliminate any other possible effects of light (such as perception through the epiphysis and related brain parts), photography was done with ultraviolet light (Bardach, Johnson, \& Todd, 1967).

The relative distribution of chemicals introduced into the tank was roughly mapped by repeated photography of the patterns of fluorescein dye released at the same points and in the same manner as the chemical stimuli. The stimuli employed were a number of amino acids which had been ascertained as taste and/or smell stimulants through electrophysiological experiments. Complex food scents such as filtered liver extract were also used. The relative roles of olfaction and taste in orientation was tested by using some animals with intact smell and taste senses as well as others that had had their olfactory sense eliminated by cautery of nares.

The ability of the fishes to orient themselves in the concentration gradient of tasty bulk messengers we used was not impaired by the elimination of their olfactory faculties. The most notable features of orientation by taste, as ascertained from their swimming paths while locating a point source of a chemical stimulus were: (1) Search in a current carrying food scent to them involved more deviation from an almost straight line between their initial position and the stimulus source than did search in still water. In still water trials, our animals with their concentration of taste sensors at the anterior end and an intact relatively even distribution of taste sensors along their flanks and backs first detected the stimulus and followed its gradient in a relatively straight line (FIGURE 7a). Although a current may carry the stimulus more quickly over greater distances, the gradient is not concentric and may be disturbed by eddies. Thus, our animals in their orientation to current-borne stimuli swam over more sinuous and complicated paths (FIGURE 7b). (2) Unilateral deprivation of the taste sense led to increased circling towards the intact side (FIGURE 7c). Fishes bilaterally but evenly deprived of some of 
their taste buds, however, still followed the gradient without deviation, especially in still water (FIGURE 7d). Both of these experiments support the theory that the comparison of sensory inputs from right and left is a major component in orientation (see also Bardach, Todd, \& Crickmer, 1967).

The fact that bullheads and other fishes with external taste sensors swim relatively slowly is apparently an attribute that enhances the orienting function
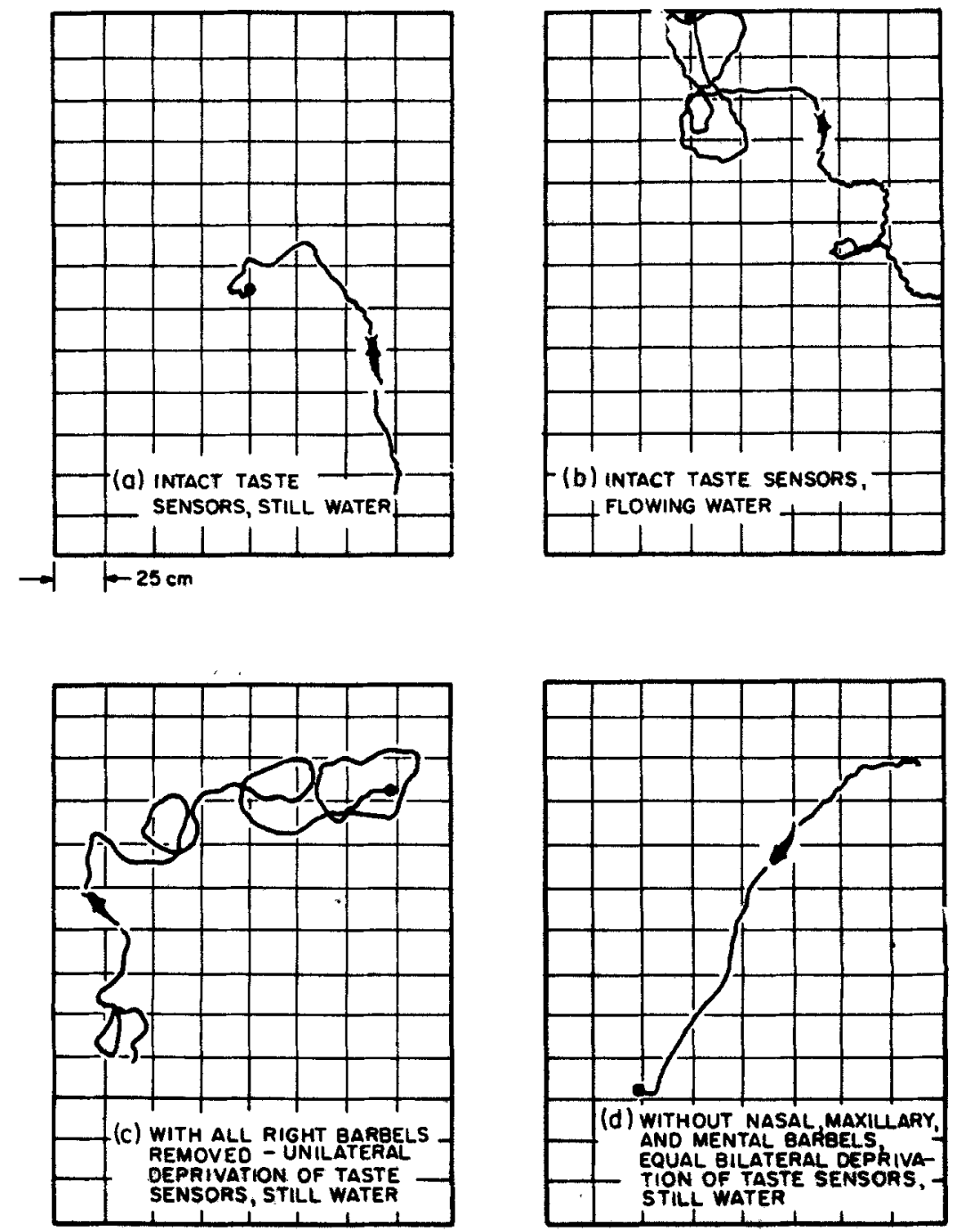

FIGURe 7. Search patterns of optically blinded brown bullheads with cauterized nares, locating a source of bulk messengers by means of taste alone. 
of their taste sensors. Faster swimming fishes, however, seize on currents as an advantage. Experiments by Kleerekoper (1967) showed that many species of fish found a source of scent with greater accuracy when the stimulus was released in currents of somewhat different velocity than those to which the animal was habituated; the mode of current detection has not been ascertained.

Intriguing as the bullhead's orientation by taste may be, especially since taste has not been considered a true distance sense, their performance is not as impressive as that of some of their relatives either with longer barbels and/or with an even higher density of external taste buds (FIGURE 5). For instance, the air-breathing catfish Clarias possesses both attributes as well as an acute sense of smell; it searches for sources of chemical stimuli several times faster than bullheads (A. Holl, personal communication).

Detection and orientation by bulk messenger sensors have been described here in relation to only one behavioral aspect, feeding. Olfaction, which relies on bulk messenger transfer, is also involved in other behavioral aspects of fishes. The best known of them so far are the chemical home-stream signatures which salmon detect with their noses (Hara, Ueda, and Gorbman, 1965) and on which they apparently rely in returning to their home water to spawn. Furthermore, among the Cichlids the brood-guarding parents recognize their own young by smell (Kuhme, 1963).

Equally interesting, though not entirely unsuspected, is the existence among fishes of bulk messengers carrying information of social significance. It has been established in our laboratory that one fish recognizes another individual of the same species by its particular scent (Todd, Atema, \& Bardach, 1967). It appears that certain substances primarily in the fishes' slime are involved. These examples suggest that bulk messenger transfer in the aquatic environment is very important and in need of further intensive investigation.

\section{Acknowledgments}

The authors are grateful to Paula Willoughby for her patience and thoroughness in counting taste buds.

This work was supported by NIH grant NB 04687.

\section{References}

Bardach, J. E., G. H. Johnson \& J. H. Tond. 1967. A new laboratory method for tracking aquatic animals. Medical and Biological Illustration 17 (2).

Bardach, J. E., J. H. Todd, \& R. Crickmer. 1967. Orientation by taste in fish of the genus Ictalurus. Science 155: 1276-78.

Döving, K. B. 1966. Efferent influence upon activity of single neurons in the olfactory bulb of the burbot. J. Neurophysiology 29: 675-83. 
GLASER, D. 1966. Untersuchungen ueber absoluten Geschmacksschwellen von Fischen, Z. Vergl. Physiol. 52: 1-25.

HARA, T. J., K. UEDA, \& A. GoRbman. 1965. Electroencephalographic studies of homing salmon. Science 149: 884-5.

KLEEREKOPER, H. 1967. Some effects of olfactory stimulation on locomotor patterns in fish. Olfaction and Taste $22: 625-45$.

Kuнme, W. 1963. Chemisch ausgelöste Brutpflege- und Schwarmreaktion bei Hemichromis bimaculatus (Pisces-704). Z. Tierphysiol. 20: 688.

TeichmanN, H. 1962. Die Chemorezeption der Fische, Erg. d. Biol. 25: 177-205.

Tod, J. H., J. ATEma, \& J. E. BARdACH. 1967. Chemical communication in social behavior of a fish, the yellow bullhead (Ictalurus natalis). Science (in publication). 